\title{
O ACESSO À JUSTIÇA COMO DIREITO FUNDAMENTAL: A DESJUDICIALIZAÇÃO PARA A CONSECUÇÃO DOS DIREITOS HUMANOS
}

\author{
ACCESS TO JUSTICE AS A FUNDAMENTAL RIGHT: \\ 'DEJUDICIALIZATION' FOR THE ACHIEVEMENT OF HUMAN RIGHTS
}

\author{
Anderson Ricardo Fogaça ${ }^{1} *$ \\ José Laurindo de Souza Netto ${ }^{2} * *$ \\ Letícia de Andrade Porto $^{3} * * *$
}

\begin{abstract}
SUMÁRIO 1 Introdução; 2. As condenações do Brasil perante a Corte Interamericana de Direitos Humanos em face da demora da prestação jurisdicional nacional; 3. O acesso à justiça como direito fundamental e a desjudicialização como solução; 4. Conclusão.

RESUMO: O grande número de ações judiciais que ingressam no âmbito dos poderes judiciários estaduais brasileiros é motivo de questionamento quanto à efetiva prestação jurisdicional alcançada. Em razão da demora da prestação jurisdicional, o Brasil foi condenado por diversas vezes no âmbito da Corte Interamericana de Direitos Humanos. O objeto da pesquisa repousa na premente necessidade de releitura do direito fundamental de acesso à justiça para englobar o aspecto da desjudicialização. O método de pesquisa adotado é o dialético, realizado através de análise bibliográfica e de dados fornecidos pelo CNJ.
\end{abstract}

Palavras-Chave: Acesso à justiça; Desjudicialização; Direitos Humanos; Justiça Brasileira; Corte Interamericana de Direitos Humanos.

\begin{abstract}
The large number of lawsuits that enter the scope of the Brazilian state courts is a reason for questioning the effective judicial provision achieved. Due to the delay in the judicial provision, Brazil has been condemned several times within the scope of the Inter-American Court of Human Rights. The object of this research rests on the need of a re-reading of the fundamental right of access to justice to encompass the aspect of 'dejudicialization'. The research method adopted is the dialectic, carried out through bibliographic and data provided by CNJ.
\end{abstract}

Key-Words: Access to Justice; Dejudicialization; Human Rights; Brazilian Justice; Inter-american Court of Human Rights.

\footnotetext{
1 * Juiz de Direito em $2^{\circ}$ Grau e Juiz Auxiliar da Presidência do Tribunal de Justiça do Estado do Paraná. Doutorando em Direito pela Universidade Federal do Paraná (UFPR). Mestre em Direito pelo Centro Universitário Internacional (UNINTER). Professor licenciado da Escola da Magistratura do Paraná. E-mail: andersonfog@yahoo.com.br ORCID: https://orcid.org/0000-0001-8495-9443 / LATTES: http://lattes.cnpq.br/9343656785887913

2 ** Desembargador e Presidente do Tribunal de Justiça do Estado do Paraná. Pós-doutor pela Faculdade de Direito da Universidade Degli Studi di Roma - La Sapienza. Estágio de Pós-doutorado em Portugal. Professor permanente no Mestrado da Universidade Paranaense - UNIPAR. E-mail: jln@tjpr.jus.br ORCID: https://orcid.org/0000-0002-6950-6128 / LATTES: http://lattes.cnpq.br/8509259358093260.

3 ***Assessora da Presidência do Tribunal de Justiça do Paraná (TJPR). Mestranda em Direitos Humanos e Democracia pela Universidade Federal do Paraná (UFPR). Especialista em Ministério Público e Estado Democrático de Direito pela Fundação Escola do Ministério Público do Paraná (FEMPAR). Bacharel em Direito e em Relações Internacionais. E-mail: leticia.porto21@ gmail.com. ORCID: https://orcid.org/0000-0002-76256139 / Lattes: http://lattes.cnpq.br/4957444327036996
} 


\section{INTRODUÇÃO}

O exorbitante número de ações judiciais que tramitam no âmbito dos Poderes Judiciários estaduais revela verdadeiro desafio ao cumprimento da tutela efetiva dos direitos do cidadão. Ao ingressar com a demanda perante o Poder Judiciário, o cidadão busca uma prestação jurisdicional adequada, em respeito à duração razoável de seu processo, observadas as garantias constitucionais. Todavia, o acesso à justiça, em sua via tradicional judicial, esbarra em constantes limitações que geram frustrações cotidianas.

Premente a necessidade da "desjudicialização" de casos outrora litigiosos, e que podem encontrar solução efetiva e célere pela via extrajudicial. O objetivo deste trabalho consubstancia-se na verificação do acesso à justiça e sua relação com a possibilidade da "desjudicialização" de algumas demandas, principalmente as decorrentes de direito civil entre pessoas físicas, como os litígios envolvendo o Direito de Família. Isso porque, "o juiz não pode ser visto como a primeira opção para os litigantes, mas, sim, como a última" (CADIET, 2015, p. 52; FOGAÇA, 2020, p. 100).

Como forma de alcançá-lo, a metodologia utilizada perpassa análises das condenações do Brasil perante a Corte Interamericana de Direitos Humanos em decorrência da morosidade da tramitação dos processos judiciais, em consonância com o direito humano de acesso à justiça e a tutela efetiva e célere dos direitos das vítimas. O Brasil, como signatário da Convenção Americana de Direitos Humanos, submeteu-se à jurisdição da Corte IDH, figurando em casos apreciados pelo órgão judicial, envolvendo a violação de direitos humanos. A morosidade da tramitação processual no Poder Judiciário brasileiro, na atualidade, constitui verdadeiro óbice ao acesso efetivo à justiça e à prestação da tutela jurisdicional adequada, podendo, inclusive, caracterizar uma violação ao direito fundamental disposto no art. 5, inciso XXXIV da Constituição Federal de 1988. De igual modo, a proteção judicial, disposta no art. 25 da Convenção Americana, tutela o recurso efetivo e rápido de qualquer pessoa perante os juízes e tribunais competentes, contra atos que violem seus direitos fundamentais, sejam eles resguardados pela Constituição ou pela Convenção Americana. Também serão analisados dados promovidos pelo Conselho Nacional de Justiça, 
datados de 2020, sobre a morosidade judicial e o acesso à justiça brasileira, em suas várias instâncias.

Nesse norte, a hipótese da presente pesquisa concentra-se em verificar se o Poder Judiciário brasileiro tem avançado à resolutividade, através da resolução de demandas pela via extrajudicial. Assim sendo, a pergunta de pesquisa questiona: É possível afirmar que o acesso à justiça brasileira encontra novos caminhos além da jurisdição contenciosa?

A justificativa da pesquisa repousa na necessidade de repensar a prestação da tutela jurisdicional através do acesso à justiça por outras vias, céleres e efetivas, por meio de autocomposição ou serventias extrajudiciais. Os dados analisados, provenientes do Relatório Justiça em Números, promovidos pelo CNJ em 2020, apontam para o esgotamento da via tradicional de resolução de litígios. O futuro do Poder Judiciário deve ser pautado pela efetividade, evitando que a morosidade processual se torne uma violação aos direitos humanos, e uma limitação ao acesso à justiça. Dessa forma, busca-se um novo horizonte ao Poder Judiciário Brasileiro, de forma a tornar a via judicial a ultima ratio para resolução dos conflitos.

O presente artigo foi pautado no método dialético, mediante análise bibliográfica e de dados, com o intuito de demonstrar que o acesso à justiça representa um importante direito fundamental e humano, que deve ser efetivado, garantido e respeitado pelos Estados signatários da Convenção Americana de Direitos Humanos.

\section{AS CONDENAÇÕES DO BRASIL PERANTE A CORTE INTERAMERICANA DE DIREITOS HUMANOS EM FACE DA DEMORA DA PRESTAÇÃO JURISDICIONAL NACIONAL}

Os direitos humanos merecem destaque nos tratados internacionais que o Brasil é signatário, como a Declaração Internacional de Direitos Humanos, firmada pela Organização das Nações Unidas (ONU), em 1948. A nível regional, foi criada a Organização dos Estados Americanos (OEA), também em 1948, para integrar as 35 (trinta e cinco) nações do continente americano, dentre as quais o Brasil (ORGANIZAÇÃO DOS ESTADOS AMERICANOS, 2021; CAMBI, PORTO, 2019-a).

A aprovação da Convenção Americana de Direitos Humanos (CADH), conhecida 
como Pacto de San José da Costa Rica, em 1969, trouxe aos Estados signatários da Convenção, uma série de deveres e direitos (CAMBI, PORTO, 2019-a).

O Sistema Interamericano de Direitos Humanos é composto pela Comissão Interamericana de Direitos Humanos $(\mathrm{CIDH})^{4}$ e pela Corte Interamericana de Direitos Humanos (Corte IDH), órgão responsável por processar e julgar os Estados-parte da CADH por violações de direitos de cidadãos que tenham sofrido qualquer violação de seus direitos no âmbito da jurisdição de um dos Estados parte da Convenção Americana - CADH (MAZZUOLI, 2015, p. 48-49).

$\mathrm{O}$ art. 26 da CADH afirma que os Estados-partes se comprometem a adotar, tanto no âmbito interno quanto no internacional, as providências necessárias para conseguir o desenvolvimento progressivo e a plena efetividade dos direitos constantes da Carta da Organização dos Estados Americanos, inclusive para prevenir a violação dos direitos humanos (MAZZUOLI, 2015, p. 48-49). Ademais, o art. 31, item 3, da Convenção de Viena, aprovada em 23 de maio de 1969, dispõe que os tratados internacionais devem ser interpretados progressivamente, levando-se em consideração todo acordo e prática posterior entre as partes na aplicação do tratado (CAMBI, PORTO, 2019-a).

Ao sujeitar-se à jurisdição da Corte IDH, e nos termos do denominado bloco de constitucionalidade ( $\operatorname{art.} 5^{\circ}, \S 2^{\circ}, \mathrm{CF}$ ), o país amplia o rol de direitos fundamentais e o espaço de diálogo com a comunidade internacional. A jurisdição brasileira, devendo-se guiar pelo princípio pro persona e basear-se na cooperação internacional, pode aumentar a efetividade dos direitos humanos (CAMBI, PORTO, FACHIN, 2020).

\footnotetext{
${ }^{4}$ Dentre as atribuições da CIDH, estão: i) receber, analisar e investigar petições individuais que alegam violações dos direitos humanos (arts. 44 a 51 da CADH); ii) observar o cumprimento geral dos direitos humanos nos Estados membros, e quando considerar conveniente, publicar as informações especiais sobre a situação em um estado específico; iii) realizar visitas in loco aos países para aprofundar a observação geral da situação, e/ou para investigar uma situação particular; tais podem resultar na preparação de um relatório respectivo, que é publicado e enviado à Assembléia Geral; iii) estimular a consciência dos direitos humanos nos países da América (v.g., pela publicação de estudos sobre temas específicos como a situação dos direitos humanos das mulheres, dos imigrantes e dos povos indígenas; iv) realizar e participar de conferências e reuniões com diversos tipos de representantes de governo, universitários e organizações não governamentais para difundir e analisar temas relacionados com o sistema interamericano de direitos humanos; v) fazer recomendações aos Estados membros da OEA acerca da adoção de medidas para contribuir com a promoção e garantia dos direitos humanos; vi) requerer aos Estados membros que adotem "medidas cautelares" específicas para evitar danos graves e irreparáveis aos direitos humanos em casos urgentes, bem como solicitar que a Corte IDH requeira "medidas provisionais" dos Governos em casos urgentes de grave perigo às pessoas, ainda que o caso não tenha sido submetido à Corte; vii) remeter os casos à jurisdição da Corte Interamericana e atuar frente à Corte em determinados litígios; viii) solicitar "Opiniões Consultivas" à Corte Interamericana sobre aspectos de interpretação da CADH (ORGANIZAÇÃO DOS ESTADOS AMERICANOS. Quem é a CIDH. Disponível em: http://https://cidh.oas.org/que.port.htm. Acesso em 06 fev. 2021).
} 
O Brasil submeteu-se à jurisdição contenciosa da Corte Interamericana de Direitos Humanos (Corte IDH), via Decreto n 4.463 de 2002, e passou a figurar no pólo passivo das demandas do Sistema Regional. Isso resultou em obrigações de ajustes internos para que normas brasileiras pudessem se coadunar com a Convenção Americana de Direitos Humanos $(\mathrm{CADH})$, o que reforça a necessidade de respeitar os direitos humanos no âmbito nacional. Afinal, o descumprimento da decisão da Corte IDH implica em violação do sistema de proteção dos direitos humanos e responsabilização do Estado no plano internacional (CAMBI, PORTO, 2019-b).

O respeito aos precedentes fixados pela Corte IDH é uma forma de assegurar os direitos humanos dentro dos Estados, além de promover a continuidade, o dinamismo e a coerência das decisões exaradas pela Corte IDH. Assim o sendo, forma-se uma unidade normativa que deve ser aplicada a todos os Estados parte, como pauta vinculante às jurisdições domésticas (CAMBI, PORTO, 2019-a).

Apesar da necessidade de cumprimento do disposto na $\mathrm{CADH}$, da imperiosa observância dos precedentes da Corte IDH e da importância do exercício do controle de convencionalidade, o Brasil tem sido acionado, com frequência, pelo descumprimento tanto de tratados de direitos humanos quanto de respectivas decisões internacionais (CAMBI, PORTO, 2020).

Até o início de 2021, o Brasil já havia sido condenado dez vezes pela Corte IDH, em questões envolvendo violência resultante de movimentos de reforma agrária ${ }^{5}$, trabalho escravo e servidão por dívidas ${ }^{6}$, tratamento desumano em relação à saúde de pessoas vulneráveis/deficientes ${ }^{7}$, desaparecimento forçado de pessoas durante operações militares na década de $1970^{8}$ e mortes no período ditatorial brasileiro (de 1964 a 1985) ${ }^{9}$, violência policial $^{10}{ }^{11}$, demarcação de terras indígenas ${ }^{12}$ e, mais recentemente, omissão estatal decorrente da ausência de fiscalização em uma fábrica de fogos, o que resultou em sua

\footnotetext{
${ }^{5}$ Caso Escher e Outros Vs. Brasil. Sentença de 6 de julho de 2009; Caso Garibaldi Vs Brasil. Sentença de 23 de setembro de 2009.

${ }^{6}$ Caso Trabalhadores da Fazenda Brasil Verde vs. Brasil. Sentença de 20 de outubro de 2016.

${ }^{7}$ Caso Ximenes Lopes Versus Brasil. Sentença de 4 de julho de 2006.

${ }^{8}$ Caso Gomes Lund e outros ("Guerrilha do Araguaia”) vs. Brasil. Sentença de 24 de novembro de 2010.

${ }^{9}$ Caso Herzog e outros Vs. Brasil. Sentença de 15 de março de 2018.

${ }^{10}$ Caso Nogueira de Carvalho e Outro Versus Brasil. Sentença de 28 de Novembro de 2006.

${ }^{11}$ Caso Favela Nova Brasília Vs Brasil. Sentença de 16 de fevereiro de 2017.

${ }^{12}$ Caso do Povo Indígena Xucuru e seus membros vs. Brasil. Sentença de 5 de fevereiro de 2018.
} 
explosão e morte de diversos trabalhadores e crianças $^{13}$.

Ao lançar um olhar apurado nas condenações sofridas, é comum, infelizmente, a constatação da demora na prestação jurisdicional brasileira, o que obsta à vítima, ou aos seus familiares, de alcançarem seus direitos e reparações. Em consonância com os casos julgados pela Corte IDH, a CADH determina a possibilidade de acesso aos tribunais em face de atos que violem qualquer direito fundamental previsto constitucionalmente, pela lei ou pela própria Convenção, mesmo que advenham de autoridades no exercício de suas funções ${ }^{14}$. De maneira semelhante, a Declaração Universal dos Direitos Humanos impõe ao sistema de justiça a proteção contra atos que violem qualquer direito fundamental ${ }^{15}$.

$\mathrm{O}$ artigo 8 da $\mathrm{CADH}$ estabelece as garantias judiciais necessárias à existência do devido processo legal, no qual prevê o acesso à justiça a partir do dever do Estado em garantir direitos observando um prazo razoável, vedando "qualquer medida interna que imponha custos ou dificulte o acesso de indivíduos ao sistema de Justiça" (LOPES, AMADO, GONZÁLEZ, RÉBORA, 2021). De forma semelhante, o artigo 25 da Convenção Americana estipula a proteção judicial, qual seja "a obrigação estatal de oferecer um recurso efetivo [...] contra quaisquer atos violatórios de direitos fundamentais" (LOPES et al, 2021, p. 31-32).

Um caso emblemático, julgado pela Corte Interamericana de Direitos Humanos em 2006, no qual o Brasil foi condenado, versava sobre a situação desumana e degradante vivida pela vítima - Damião Ximenes Lopes, portador de deficiência mental -, em razão de sua internação em um hospital psiquiátrico privado que operava no âmbito do Sistema Único de Saúde, em Sobral/CE. A situação de vulnerabilidade da vítima, decorrente da deficiência mental, agravou a situação, tendo sofrido sucessivos golpes e ataques contra sua integridade pessoal, o que resultou na sua morte - três dias após a internação. A Corte Interamericana de Direitos Humanos, em sua sentença, reiterou que,

\footnotetext{
${ }^{13}$ Caso Empregados da Fábrica de Fogos de Santo Antônio de Jesus e seus familiares Vs. Brasil. Sentença de 15 de julho de 2020.

14 "Art. 25. 1. Toda pessoa tem direito a um recurso simples e rápido ou a qualquer outro recurso efetivo, perante os juízes ou tribunais competentes, que a proteja contra atos que violem seus direitos fundamentais reconhecidos pela constituição, pela lei ou pela presente Convenção, mesmo quando tal violação seja cometida por pessoas que estejam atuando no exercício de suas funções oficiais". ORGANIZAÇÃO DOS ESTADOS AMERICANOS. Convenção Americana de Direitos Humanos. Acesso em: 11 fev. 2021. Disponível em: https://www.cidh.oas.org/basicos/portugues/c.convencao_americana.htm.

15 "Artigo VIII - Todo ser humano tem direito a receber dos tribunais nacionais competentes remédio efetivo para os atos que violem os direitos fundamentais que lhe sejam reconhecidos pela constituição ou pela lei". ORGANIZAÇÃO DAS NAÇÕES UNIDAS. Declaração Universal dos Direitos Humanos. Acesso em: 11 fev. 2021. Disponível em: https://nacoesunidas.org/wp-content/uploads/2018/10/DUDH.pdf.
} 
104. [...] os Estados devem levar em conta que os grupos de indivíduos que vivem em circunstâncias adversas e com menos recursos, tais como as pessoas em condição de extrema pobreza, as crianças e adolescentes em situação de risco e as populações indígenas, enfrentam um aumento do risco de padecer de deficiências mentais, como era o caso do senhor Damião Ximenes Lopes. É direto e significativo o vínculo existente entre a deficiência, por um lado, e a pobreza e a exclusão social, por outro. Entre as medidas positivas a cargo dos Estados encontram-se, pelas razões expostas, as necessárias para evitar todas as formas de deficiência que possam ser prevenidas e estender às pessoas que padeçam de deficiências mentais o tratamento preferencial apropriado a sua condição (CORTE INTERAMERICANA DE DIREITOS HUMANOS, 2006) ${ }^{16}$.

Em seu voto apartado, o Juiz Antônio Augusto Cançado Trindade considerou que o direito de acesso à Justiça deve ser reconhecido como um Direito à Pronta Prestação Jurisdicional, garantia que não restou perfectibilizada no caso Ximenes Lopes Vs. Brasil. A denúncia foi apresentada pelo representante do Ministério Público estadual em 27 de março de 2000, sendo que, passados mais de quatro anos do oferecimento da peça inicial, não havia sido emitida a sentença na primeira instância ${ }^{17}$.

$\mathrm{Na}$ sentença condenatória exarada pela Corte IDH, foram reconhecidas as violações aos direitos à vida e à integridade pessoal de Damião Ximenes Lopes, além dos direitos às

\footnotetext{
${ }^{16}$ Neste ponto, é interessante lançar um olhar sobre o voto apartado do Juiz Cançado Trindade: "40. As obrigações de proteção, - ainda mais em uma situação de alta vulnerabilidade da vítima como a presente, revestem-se de caráter erga omnes (par. 85), abarcando também as relações interindividuais, tendo presente o dever do Estado de prevenção e de devida diligência, sobretudo em relação a pessoas que se encontram sobre seus cuidados. A saúde pública é um bem público, não uma mercadoria. Em meus numerosos escritos e Votos no seio desta Corte, venho expressando há tantos anos meu entendimento no sentido de que todas as obrigações convencionais de proteção revestem-se de um caráter erga omnes. É-me particularmente difícil escapar da impressão que me assalta no sentido de que em todo esse tempo talvez tenha eu escrito e continue escrevendo para os pássaros..." (CORTE INTERAMERICANA DE DIREITOS HUMANOS. Caso Ximenes Lopes versus Brasil. Op.cit).

17 "24. O direito de acesso à justiça lato sensu pressupõe o entendimento de que se trata de direito à pronta prestação jurisdicional. Sua fiel observância não se constatou no presente caso Ximenes Lopes, como se depreende claramente dos próprios fatos. Por exemplo, aos 27.03.2000 o representante do Ministério Público apresentou denúncia criminal na Comarca de Sobral contra quatro pessoas supostamente incursas nas penas do Código Penal brasileiro (artigo 136(2)) por crime de maus-tratos resultando na morte da vítima (Sr. Damião Ximenes Lopes). Dois meses depois, os promotores do Centro de Apoio Operacional dos Grupos Socialmente Discriminados da Procuradoria Geral de Justiça manifestava ao Promotor de Justiça que atuava na causa que a ampliação da denúncia constituía uma "imposição institucional e legal"; pese ao anterior, foi somente aos 22.09.2003 que, ao apresentar suas alegações finais, a Promotoria ampliou a denúncia para incluir a duas outras pessoas.
}

25. A morosidade na tramitação tão só do aditamento da denúncia se prolongou ainda mais, porquanto somente aos 17.06.2004 o Juiz de Direito da Comarca de Sobral o recebeu. [...] Naquele momento, o processo penal no cas d'espèce completava mais de 4 anos e 2 meses sem que tivesse sido emitida sequer a sentença de primeira instância". CORTE INTERAMERICANA DE DIREITOS HUMANOS. Caso Ximenes Lopes versus Brasil. Op.cit. 
garantias judiciais e à proteção judicial consagrados nos artigos $8.1^{18}$ e $25.1^{19}$ da Convenção Americana. Como forma de reparação, a Corte IDH solicitou que o Estado garanta, em um prazo razoável, a investigação e o prosseguimento processual interno, a fim de sancionar os responsáveis pelo caso (CORTE INTERAMERICANA DE DIREITOS HUMANOS, 2006).

Em 2016, o Caso Favela Nova Brasília Vs. Brasil também versou sobre o direito a um processo judicial efetivo em prazo razoável como forma de reparação às violações havidas. O caso trata da demora injustificada na investigação e punição dos responsáveis envolvidos na execução de 26 pessoas e na prática de tortura e estupro, por parte de agentes policiais, cometidos contra 3 mulheres durante abordagens policiais em outubro de 1994 e maio de 1995 na Favela Nova Brasília, no município do Rio de Janeiro (CORTE INTERAMERICANA DE DIREITOS HUMANOS, 2017).

Sobre a alegação da demora irrazoável do processo, a Corte IDH ressaltou que

217. Quanto à celeridade do processo, este Tribunal salientou que o "prazo razoável" a que se refere o artigo 8.1 da Convenção deve ser apreciado em relação à duração total do procedimento que se desenvolve até que se profira a sentença definitiva. $\mathrm{O}$ direito de acesso à justiça implica em que a solução da controvérsia se dê em tempo razoável, já que uma demora prolongada pode chegar a constituir, por si mesma, uma violação das garantias judiciais.

218. A respeito do suposto descumprimento da garantia judicial de prazo razoável no processo penal, a Corte examinará os quatro critérios estabelecidos em sua jurisprudência na matéria: i) a complexidade do assunto; ii) a atividade processual do interessado; iii) a conduta das autoridades judiciais; e iv) o dano provocado na situação jurídica da pessoa envolvida no processo [...] (CORTE INTERAMERICANA DE DIREITOS HUMANOS, 2017).

Como conclusão, inferiu-se que a "longa duração das investigações fez com que os familiares das vítimas mortas permanecessem em situação de incerteza a respeito dos

\footnotetext{
18 "Artigo 8. Garantias judiciais

1. Toda pessoa tem direito a ser ouvida, com as devidas garantias e dentro de um prazo razoável, por um juiz ou tribunal competente, independente e imparcial, estabelecido anteriormente por lei, na apuração de qualquer acusação penal formulada contra ela, ou para que se determinem seus direitos ou obrigações de natureza civil, trabalhista, fiscal ou de qualquer outra natureza". ORGANIZAÇÃO DOS ESTADOS AMERICANOS. Convenção Americana de Direitos Humanos.

19 "Artigo 25. Proteção judicial

1. Toda pessoa tem direito a um recurso simples e rápido ou a qualquer outro recurso efetivo, perante os juízes ou tribunais competentes, que a proteja contra atos que violem seus direitos fundamentais reconhecidos pela constituição, pela lei ou pela presente Convenção, mesmo quando tal violação seja cometida por pessoas que estejam atuando no exercício de suas funções oficiais". ORGANIZAÇÃO DOS ESTADOS AMERICANOS. Convenção Americana de Direitos Humanos.
} 
responsáveis pelos fatos da incursão de 1994" (CORTE INTERAMERICANA DE DIREITOS HUMANOS, 2017), razão pela qual foi considerado violado o disposto no art. 8.1 da Convenção Americana, no que diz respeito às garantias judiciais de devida diligência e prazo razoável.

Insta salientar que a demora na prestação jurisdicional constitui uma violação das garantias judiciais, ao passo que o acesso à justiça deve ser considerado como um direito fundamental e humano, consubstanciado no art. 25 da Convenção Americana.

Por outra senda, em tempos de pandemia de Covid-19, a Comissão Interamericana de Direitos Humanos regulamentou a Resolução 04/2020, que fixa diretrizes quanto ao tratamento digno dispensado às pessoas infectadas pelo vírus. Em seu parágrafo 47, dita que o acesso à justiça, nesse contexto, deve ser garantido em relação às denúncias que envolvam violação de direitos humanos das pessoas com Covid-19, devendo observar a celeridade e diligência de modo a proteger os direitos dos indivíduos infectados (COMISSÃO INTERAMERICANA DE DIREITOS HUMANOS, 2020) ${ }^{20}$.

A nível global, a Organização das Nações Unidas tem buscado inserir a resolução extrajudicial nas demandas criminais, o que deu origem à Resolução n. 2002/12 do Conselho Econômico e Social da ONU, que regulamentou princípios básicos para utilização de programas de justiça restaurativa em matéria criminal (PARANÁ, 2012).

Não se olvida que os números de ingresso de ações no Poder Judiciário brasileiro são elevados, conforme se depreende dos dados provenientes do Conselho Nacional de Justiça, no Relatório Justiça em Números - 2020. A taxa de congestionamento ${ }^{21}$, em média, dos

\footnotetext{
20 "45. Para garantizar el derecho de acceso a la justicia de las personas con COVID-19 deben asegurarse recursos dirigidos a investigar de manera seria, oportuna y diligente las afectaciones a sus derechos, que incluyen irregularidades en el diagnóstico, tratamiento y rehabilitación médica recibida, atención médica en instituciones sin la debida habilitación o no aptas en razón de su infraestructura o higiene, o por profesionales que no cuenten con la debida calificación para tales actividades. [...] 47. Los procesos relacionados con denuncias de afectaciones a los derechos de las personas con COVID-19 así como la ejecución de las sanciones deben ser decididos en un plazo razonable. Cuando lo que se encuentra en juego en el proceso judicial es de crucial importancia para salvaguardar los derechos de la persona afectada, los Estados deben actuar con celeridad y diligencia excepcional, aun cuando este tipo de casos pueda significar cierto nivel de complejidad". COMISSÃO INTERAMERICANA DE DIREITOS HUMANOS. Resolución 4/20 - Derechos Humanos de las personas con Covid-19. Disponível em: https://www.oas.org/es/cidh/decisiones/pdf/Resolucion-4-20-es.pdf Acesso em: 8 mar. 2021.

21 "A taxa de congestionamento mede o percentual de processos que ficaram represados sem solução, comparativamente ao total tramitado no período de um ano. Quanto maior o índice, maior a dificuldade do
} 
Tribunais estaduais, gira em torno de 71\%. Como forma de resolver os litígios pendentes de solução, o CNJ tem incentivado a promoção de acordos por meio de conciliação (BRASIL, 2020). A resolução CNJ n. 125/2010 criou os Centros Judiciários de Solução de Conflitos e Cidadania (CEJUSCs) e os Núcleos Permanentes de Métodos Consensuais de Solução de Conflitos (NUPEMEC), em respeito ao direito ao acesso à justiça e à celeridade processual.

Em cumprimento ao disposto pelo $\mathrm{CNJ}$, foram criados vários Centros Judiciários de Solução de Conflitos e Cidadania pelo Brasil, com destaque para os três tribunais estaduais que comportam o maior número dessas iniciativas, dentre os quais o Tribunal de Justiça do Estado de São Paulo, com 231 Centros, Tribunal de Justiça de Minas Gerais, com 166 Centros e, o Tribunal de Justiça do Estado do Paraná, onde figuram 135 Centros Judiciários de Solução de Conflitos na Justiça Estadual (BRASIL, 2020).

Sobre esse ponto, é interessante lançar um olhar sobre uma iniciativa do Tribunal de Justiça do Estado do Paraná que busca assegurar a celeridade processual e o acesso à justiça aos cidadãos. A fim de garantir o fornecimento de medicamento ou tratamento de saúde por parte do Estado ou do Município, no Estado do Paraná, o Tribunal de Justiça, por meio da 2a Vice-Presidência (Gestão 2019/2020), celebrou termo de cooperação para que a Defensoria Pública e o Ministério Público promova o chamamento do ente público pelo sistema préprocessual do CEJUSC, evitando, com isso, o ajuizamento da demanda. Primeiro, convida-se o responsável pelo medicamento ou tratamento para uma audiência no CEJUSC, a qual é conduzida por um mediador judicial devidamente capacitado com as técnicas de mediação e conciliação. Obtida a transação, o juiz coordenador do CEJUSC homologa o acordo préprocessual. Caso seja negativa, a Defensoria Pública ou Ministério Público avaliará se deve ingressar ou não com a demanda judicial. Com isso, o cidadão tem seu conflito resolvido no menor tempo possível, pelo próprio Poder Judiciário, concretizando-se um acesso à justiça célere, justo e efetivo (FOGAÇA, 2020, p. 106).

Todavia, não se pode olvidar que, apesar dos esforços engendrados pela Justiça Brasileira, os números totais de conciliação efetuados pelo Poder Judiciário giram em torno de $12,5 \%$ (BRASIL, 2020, p. 174). "A litigiosidade no Brasil permanece alta e a cultura da

tribunal em lidar com seu estoque de processos". BRASIL. Conselho Nacional de Justiça. Justiça em números 2020. Acesso em: 12 fev. 2021. Disponível em: https://www.cnj.jus.br/wp-content/uploads/2020/08/WEB-V3Justiça-em-Números-2020-atualizado-em-25-08-2020.pdf 
conciliação, incentivada mediante política permanente do CNJ desde 2006, ainda apresenta lenta evolução" (BRASIL, 2020, p. 174).

O acesso à justiça constitui importante mecanismo de efetivação de direitos dentro do Estado Democrático de Direito. A democracia se justifica na tutela dos direitos fundamentais intrínsecos ao bem estar social.

Insta salientar que o Código de Processo Civil, que entrou em vigor em 2016, trouxe importantes inovações nesse sentido, ao valorizar a resolução de conflitos de maneira pacífica, além de tornar obrigatória a realização de audiência prévia de conciliação e mediação. Trata-se de uma grande mudança que é, ainda timidamente, incorporada ao cotidiano jurídico.

\section{O ACESSO À JUSTIÇA COMO DIREITO FUNDAMENTAL E A DESJUDICIALIZAÇÃO COMO SOLUÇÃO}

O acesso à justiça é garantia constitucional, previsto no art. 5, inciso XXXIV da Constituição Federal de 1988. Seu amplo acesso, independentemente do pagamento de taxas, permite que o cidadão possa peticionar aos "Poderes Públicos em defesa de direitos ou contra ilegalidade ou abuso de poder" (BRASIL, 1988).

Em consonância com o exposto, a Agenda Global 2030 da Organização das Nações Unidas estabeleceu o compromisso assumido por vários países - incluído o Brasil -, no que concerne ao cumprimento de 17 objetivos para o Desenvolvimento Sustentável no mundo, até 2030. A Agenda foi recepcionada pelo Poder Judiciário Brasileiro, que se compromete com a persecução dos objetivos e metas relacionadas aos Direitos Humanos. Dentre eles, destaca-se o Objetivo 16, que busca "promover sociedades pacíficas e inclusivas para o desenvolvimento sustentável, proporcionar o acesso à justiça para todos e construir instituições eficazes, responsáveis e inclusivas em todos os níveis" (BRASIL, 2020, p. 253).

A busca por uma "desjudicialização" das demandas litigiosas, e sua transposição para uma justiça restaurativa, através de métodos autocompositivos, ou até mesmo via comunidade de prática, guarda consonância com o acesso à justiça de maneira resolutiva e célere, 
conforme disciplina o Direito Internacional dos Direitos Humanos. Dessa forma, a construção de uma sociedade pacífica e inclusiva pressupõe cooperação dos cidadãos em um diálogo aberto para a consecução de objetivos em comum.

Portanto, a desjudicialização vem sendo utilizada nesse contexto, no qual é considerada como uma forma de acesso à justiça e que pode ser resolvida fora do ambiente judicial, pelos próprios indivíduos, fato que, para Mônica Bonetti Couto e Luana Pedrosa de Figueiredo Cruz, é definido como uma "transferência da competência da resolução de um litígio do tribunal para instâncias não judiciais", reduzindo-se a taxa de congestionamento de processos (COUTO, CRUZ, 2017, p. 405-425; FOGAÇA, 2020, p. 101).

Nesse norte, a desjudicialização abarca não apenas interesses quantitativos, econômicos e de gestão. Isso porque um menor número de litígios tem sentido de economia para o orçamento do Estado (CADIET, p. 41; FOGAÇA, 2020, p. 101).

A ideia da "popularização do Judiciário", proposta por Ada Pellegrini Grinnover (1999) caminha em consonância com a evolução do processo na sociedade. Para ela, o acesso à justiça não pode se restringir somente ao mero ingresso aos tribunais, devendo ser mais célere, pois a mora seria cúmplice da impunidade (GRINNOVER, 1999; FOGAÇA, 2020, p. 103).

O acesso à justiça é classicamente delineado a partir de três dimensões básicas. A primeira se refere à própria procura por assistência jurídica, propiciando o ingresso daquelas pessoas menos favorecidas ao Poder Judiciário para que façam valer seus direitos individuais. A segunda das dimensões, por sua vez, se conecta à luta pela salvaguarda de direitos difusos e coletivos. A terceira dimensão, por fim, adota um ponto de vista mais amplo, pois, além de incluir os aspectos das noções anteriores, avança para debater as formas de acesso à justiça. A criação de órgãos especializados e a institucionalização de formas socialmente adequadas de resolução de litígios, alheias à tradicional heterocomposição da lide por um terceiro imparcial (Estado-juiz), estão calcadas, justamente, nessa última dimensão (FELTEN, 2014, p. 30-41).

Há tempos nota-se que o acesso à justiça vem sendo utilizado de maneira predatória: os jurisdicionados enxergam a ação judicial como a porta de entrada para a resolução de seus problemas, e não como última ratio. Essa cultura da litigiosidade vem implicando num considerável aumento nos gastos públicos com demandas individuais, o que não se coaduna 
com um sistema de justiça sustentável — que reclama acessibilidade por todos e produção de resultados que sejam individual e socialmente justos.

Deve-se considerar também o uso predatório do sistema de Justiça pelos réus, que aproveitam a morosidade que eles próprios causam para obter vantagens. Isso ocorre com mais intensidade nos litígios de massa, envolvendo os grandes prestadores de serviços públicos, instituições financeiras e entes públicos.

Cada processo em trâmite, no Brasil, tem um valor muito elevado. Se considerarmos que o Poder Judiciário, em todas suas esferas de competência, segundo dados do Justiça em Números 2020, do Conselho Nacional de Justiça, teve um total de despesa, em 2019, de cerca de 100,2 bilhões de reais, equivalente a 1,5\% do Produto Interno Bruto (PIB) nacional, e que 2019 foi finalizado com 77,1 milhões de processos em trâmite, conclui-se que cada processo, do mais simples ao mais complexo, custa, em média, $\mathrm{R} \$ 1.299,61$ por ano, valor gasto na manutenção de sua estrutura física, de tecnologia e de recurso humano (BRASIL, 2020).

Segundo o mesmo relatório Justiça em Números 2020, o Poder Judiciário custou, em 2019 , R \$ 479,16 por habitante, valor extremamente alto para uma sociedade tão desigual como a brasileira, visto que este valor corresponde a, aproximadamente, 47,5\% do salário mínimo nacional (BRASIL, 2020).

A manutenção do sistema de justiça tem um elevado custo de transação - sensível nas demandas sanitárias - exigindo-se que se torne economicamente sustentável e mais eficiente para que o Poder Judiciário se ocupe de demandas mais complexas e sensíveis para os indivíduos, devendo ser evitada a judicialização de questões que poderiam ser resolvidas fora do sistema de justiça (extrajudicialmente) ou de forma pré-processual pelo Poder Judiciário.

Os altos índices de acervo processual, conforme se depreende da leitura dos dados do CNJ - Justiça em Números 2020 -, demandam uma solução eficaz. Não se busca uma solução paliativa - como a contratação de servidores que auxiliem nas demandas, que, inicialmente, absorvem parte dos litígios que ingressam na esfera judicial -, mas, sim, alcançar uma resposta definitiva, de forma a migrar ações outrora judiciais para soluções em vias alternativas, como através das serventias extrajudiciais, em casos que envolvam a tutela de direitos civis de pessoas capazes.

Aqui, podem ser citadas outras formas de acesso à justiça sem a necessidade de ingresso premente na esfera judicial, como a possibilidade de reconhecimento de paternidade 
perante o Registro Civil. O Provimento No 16 de 17/02/2012, do CNJ, busca facilitar o reconhecimento espontâneo de paternidade e a indicação dos supostos pais de pessoas que já se acharem registradas sem paternidade estabelecida perante o registro civil (BRASIL, 2012).

Nesse norte, o Código de Processo Civil de 2015 trouxe importantes inovações almejando a celeridade processual e a desjudicialização, como a previsão do divórcio consensual, separação consensual e a extinção consensual de união estável, mediante escritura pública, prescindindo de homologação judicial, em não havendo nascituro ou filhos incapazes $^{22}$. Da mesma forma, a ação de divisão e demarcação de terras particulares, prevista nos artigos 569 a 573 do Código de Processo Civil - CPC, pode ser realizada por escritura pública quando todos os interessados forem maiores, capazes e concordes ${ }^{23}$. Também, proceder-se-á à lavratura de escritura pública de inventário e partilha quando todos os interessados forem capazes e concordes, limitando-se o inventário judicial quando o testamento ou os interessados forem incapazes, conforme disciplina o artigo 610 do CPC.

Em se falando da prestação de uma tutela rápida e eficaz, não se olvida da premente necessidade de sua realização em casos de violência doméstica. Cabe mencionar as alterações previstas na Lei 11.340/06, popularmente conhecida como Lei Maria da Penha, que dizem respeito à celeridade processual no que tange à mulher vítima de violência doméstica, e que se encontra em situação de risco atual ou iminente. O delegado de polícia e o policial podem determinar o afastamento do agressor do lar e da convivência com a vítima, de maneira a conceder rapidez e garantir a segurança da ofendida ${ }^{24}$. Sabe-se, que nesses casos, cada minuto

\footnotetext{
22 "Art. 733. O divórcio consensual, a separação consensual e a extinção consensual de união estável, não havendo nascituro ou filhos incapazes e observados os requisitos legais, poderão ser realizados por escritura pública, da qual constarão as disposições de que trata o art. 731 .
}

$\S 1^{\circ}$ A escritura não depende de homologação judicial e constitui título hábil para qualquer ato de registro, bem como para levantamento de importância depositada em instituições financeiras". BRASIL. Código de Processo Civil. 2015.

23 "Art. 571. A demarcação e a divisão poderão ser realizadas por escritura pública, desde que maiores, capazes e concordes todos os interessados, observando-se, no que couber, os dispositivos deste Capítulo". BRASIL. Código de Processo Civil. 2015.

24 "Art. 12-C. Verificada a existência de risco atual ou iminente à vida ou à integridade física da mulher em situação de violência doméstica e familiar, ou de seus dependentes, o agressor será imediatamente afastado do lar, domicílio ou local de convivência com a ofendida: I - pela autoridade judicial; II - pelo delegado de polícia, quando o Município não for sede de comarca; ou III - pelo policial, quando o Município não for sede de comarca e não houver delegado disponível no momento da denúncia. $\$ 1^{\circ}$ Nas hipóteses dos incisos II e III do caput deste artigo, o juiz será comunicado no prazo máximo de 24 (vinte e quatro) horas e decidirá, em igual prazo, sobre a manutenção ou a revogação da medida aplicada, devendo dar ciência ao Ministério Público concomitantemente". BRASIL. LEI $N^{\circ} 11.340$, DE 7 DE AGOSTO DE 2006. Cria mecanismos para coibir a 
é precioso e a espera pela decisão judicial concedente de medida protetiva pode significar consequências graves para a ofendida. Ademais, a espera pela decisão judicial poderia inibir a vítima a proceder pela procura à autoridade policial, em função da sua exposição ao agressor.

Conforme leciona Nucci (2019),

Teve a referida lei a cautela de prever a comunicação da medida ao juiz, no prazo máximo de 24 horas, decidindo em igual prazo, para manter ou revogar a medida, cientificando o Ministério Público. Nota-se a ideia de preservar a reserva de jurisdição, conferindo à autoridade judicial a última palavra, tal como se faz quando o magistrado avalia o auto de prisão em flagrante (lavrado pelo delegado de polícia). Construiu-se, por meio de lei, uma hipótese administrativa de concessão de medida protetiva - tal como se fez com a lavratura do auto de prisão em flagrante (e quanto ao relaxamento do flagrante pelo delegado). Não se retira do juiz a palavra final. Antecipa-se medida provisória de urgência (como se faz no caso do flagrante: qualquer um pode prender quem esteja cometendo um crime).

Essa flexibilização do processo permite respostas efetivas e céleres. Quanto menos demandas, menor a estrutura que será necessária para o regular desenvolvimento das atividades próprias do Poder Judiciário. Evidente que os resultados de uma desjudicialização serão obtidos em longo prazo, sendo as próximas gerações beneficiárias da diminuição do número de processos e da maior celeridade no julgamento das demandas (FOGAÇA, 2020, p. 103).

\section{CONCLUSÃO}

Percebe-se que o Poder Judiciário evoluiu nos últimos anos em sua gestão, tendo alcançado um resultado positivo com a diminuição de processos em 2019 e o crescente aumento da produtividade dos juízes brasileiros. O relatório Justiça em Números - 2020 trouxe que cada juiz, em 2019, solucionou 2.107 processos, ou seja, uma média de 8,4 casos solucionados por dia útil, sem descontar períodos de férias e recessos - um aumento de 24,2\% em relação ao ano de 2014. Todavia, os números divulgados pelo relatório do CNJ - Justiça em Números - 2020 não deixam dúvida da existência de um excesso de litigiosidade, que sobrecarrega o sistema de Justiça, provocando-o a promover e incentivar o uso de outros meios de acesso à justiça (BRASIL, 2020).

violência doméstica e familiar contra a mulher, nos termos do $\S 8^{\circ}$ do art. 226 da Constituição Federal, da Convenção sobre a Eliminação de Todas as Formas de Discriminação contra as Mulheres e da Convenção Interamericana para Prevenir, Punir e Erradicar a Violência contra a Mulher; dispõe sobre a criação dos Juizados de Violência Doméstica e Familiar contra a Mulher; altera o Código de Processo Penal, o Código Penal e a Lei de Execução Penal; e dá outras providências. 
Isso não é novidade, pois o direito de acesso à justiça está historicamente alinhado ao aspecto da rivalidade, o que faz com que a consequência natural desse direito seja o incentivo à utilização excessiva dos serviços públicos adjudicatórios, o que acaba por desencadear a morosidade do sistema de justiça (GICO JR, 2014, p. 192), e, por sua vez, o alto congestionamento de processos (GICO JR, 2019).

O alto número de processos exorbita o número de juízes provocando uma situação de desequilíbrio que, na economia, é apresentada pela influência mútua entre demanda e oferta. O período que os magistrados dispõem para a consecução das atividades judiciárias é insuficiente à luz do avanço da demanda, somado, ainda, a outros fatores (orçamento, número de juízes e servidores, quantidade de horas de trabalho diárias, direitos e deveres funcionais). O resultado deste desequilíbrio é o aumento da duração dos processos (MULLER, 2017).

Revela-se inegável que existe uma inquietação acerca do volume de processos e do dever de desempenho dos juízes para que possa haver alguma estabilização entre os processos que ingressam no sistema e os que são concluídos (COSTA, 2015, p. 354).

Nesse norte, retoma-se à pergunta de pesquisa: É possível afirmar que o acesso à justiça brasileira encontra novos caminhos além da jurisdição contenciosa?

Revela-se inegável que existem diversos meios extrajudiciais de resolução de demandas, conforme disposto na Resolução CNJ n. 125/2010, a partir da criação dos Centros Judiciários de Solução de Conflitos e Cidadania (CEJUSCs) e dos Núcleos Permanentes de Métodos Consensuais de Solução de Conflitos (NUPEMEC).

Todavia, a aderência a meios alternativos de solução de conflitos ainda encontra-se aquém do esperado, de forma que ocorre "uma lenta transformação da sociedade brasileira, no sentido de criar a cultura do consenso e da cooperação na composição das disputas, aceitandose um polissêmico conceito de justiça” (DELDUQUE, CASTRO, 2015, p. 511).

Os benefícios da desjudicialização das demandas litigiosas são facilmente vislumbrados, alcançando resultados vantajosos para as partes, como a celeridade e a economia processual, a efetiva prestação da tutela (extra)judicial, o intercâmbio instantâneo e os baixos custos de monitoramento. Tais características evitam o ingresso da ação no âmbito judiciário, com o propósito de desobstruir um lento sistema, que, frequentemente, gera frustrações às partes litigantes.

O Poder Judiciário resolutivo encontra guarida nos diplomas internacionais nos quais o Brasil é parte signatária, como a Convenção Americana de Direitos Humanos. O acesso à 
justiça prescinde da movimentação da clássica máquina judiciária, e caminha em direção à resolutividade, através da reestruturação do sistema de administração e gestão da justiça a fim de torná-lo social e economicamente sustentável.

Evita-se, assim, que as demandas alcancem o Sistema Regional de Direitos Humanos em razão da morosidade processual interna, impedindo novas condenações do Brasil perante a Corte Interamericana de Direitos Humanos pela ausência de prestação jurisdicional efetiva. A Justiça resolutiva limita o acesso genérico e, em algumas situações, descabido ao Poder Judiciário, conferindo-se, assim, o mais amplo e efetivo acesso à justiça aos que dela necessitam.

O acesso à "ordem jurídica justa" é o termo utilizado para a atualização do conceito de acesso à justiça. Se escreve a palavra "justiça” com "j” minúsculo para indicar que o acesso à justiça não é apenas o acesso aos órgãos do Poder Judiciário, mas, sim, acesso a todo o sistema que existe no âmbito oficial, privado e em toda a sociedade, que tenha aptidão para promover uma ordem jurídica mais justa (WATANABE, 2019).

\section{REFERÊNCIAS}

BRASIL. Constituição da República Federativa do Brasil. 1988.

Conselho Nacional de Justiça. Justiça em números - 2020. 2020. Disponível em: https://www.cnj.jus.br/wp-content/uploads/2020/08/WEB-V3-Justiça-em-Números-2020atualizado-em-25-08-2020.pdf Acesso em: 12 fev. 2021.

Conselho Nacional de Justiça. Provimento $N^{o} 16$ de 17/02/2012. Disponível em: https://atos.cnj.jus.br/files//provimento/provimento_16_17022012_26102012172402.pdf Acesso em: 12 fev. 2021.

Código de Processo Civil. 2015.

LEI $N^{o}$ 11.340, DE 7 DE AGOSTO DE 2006. Cria mecanismos para coibir a violência doméstica e familiar contra a mulher, nos termos do $\S 8^{\circ}$ do art. 226 da Constituição Federal, da Convenção sobre a Eliminação de Todas as Formas de Discriminação contra as Mulheres e da Convenção Interamericana para Prevenir, Punir e Erradicar a Violência contra a Mulher; dispõe sobre a criação dos Juizados de Violência Doméstica e Familiar contra a Mulher; altera o Código de Processo Penal, o Código Penal e a Lei de Execução Penal; e dá outras providências.

CADIET, Loïc. La desjudicialización: informe introductorio. In: Convenciones Procesales: Estudios sobre negocio jurídico y proceso. Lima: Raguel Ediciones, 2015. 
CAMBI, Eduardo; PORTO, Letícia de Andrade. Os precedentes da Corte Interamericana de Direitos Humanos e sua aplicação pelo Supremo Tribunal Federal. Revista dos Tribunais [Recurso Eletrônico]. São Paulo, n.1002, abr. 2019-a.

CAMBI, Eduardo; PORTO, Leticia de Andrade. O Ministério Público Resolutivo e a proteção dos direitos humanos. Belo Horizonte: D’Plácido, 2019-b.

CAMBI, Eduardo; PORTO, Leticia de Andrade. FACHIN, Melina Girardi. A (in)convencionalidade da prisão diante do não recolhimento do ICMS. In.: NORONHA, João Otávio de. AlBUQUERQUE, Paulo Pinto (Org.). Comentários à Convenção Americana sobre Direitos Humanos. São Paulo: Tirant Lo Blanch, 2020.

CAMBI, Eduardo. PORTO, Leticia de Andrade. Proteção dos Direitos Humanos e a Nova Lei de Abuso de Autoridade. In.: CAMBI, Eduardo. ALMEIDA, Gregório Assagra de (Org.). Abuso de Autoridade. Belo Horizonte: D'Plácido, 2020.

COMISSÃO INTERAMERICANA DE DIREITOS HUMANOS. Resolución 4/20 - Derechos Humanos de las personas con Covid-19. Disponível em: https://www.oas.org/es/cidh/decisiones/pdf/Resolucion-4-20-es.pdf Acesso em: 8 mar. 2021.

CORTE INTERAMERICANA DE DIREITOS HUMANOS. Caso Favela Nova Brasília Vs Brasil. $2017 . \quad$ Disponível em: https://www.corteidh.or.cr/docs/casos/articulos/seriec_333_por.pdf. Acesso em: 12 fev. 2021.

$\begin{array}{llll}\text { Reparações } & \text { e } & \text { Custas). } & \text { Disponível }\end{array}$ https://www.corteidh.or.cr/docs/casos/articulos/seriec_149_por.pdf. Acesso em: 29 jan. 2021.

. CASO EMPREGADOS DA FÁBRICA DE FOGOS DE SANTO ANTÔNIO DE JESUS E SEUS FAMILIARES VS. BRASIL. SENTENÇA DE 15 DE JULHO DE 2020 (Exceções Preliminares, Mérito, Reparações e Custas). Disponível em: https://www.corteidh.or.cr/docs/casos/articulos/seriec_407_por.pdf Acesso em: 15 fev. 2021.

. Caso do Povo Indígena Xucuru e seus membros vs. Brasil. Sentença de 5 de fevereiro de 2018. Acesso em: 15 fev. 2021. Disponível em: http://www.corteidh.or.cr/docs/casos/articulos/seriec_346_por.pdf. Acesso em: 15 fev. 2021.

. Caso Escher e Outros Vs. Brasil. Sentença de 6 de julho de 2009. Acesso em: 15 fev. 2021. Disponível em: http://www.corteidh.or.cr/docs/casos/articulos/seriec_200_por.pdf. Acesso em: 15 fev. 2021.

Caso Garibaldi Vs Brasil. Sentença de 23 de setembro de 2009. Acesso em: 15 fev. 2021. Disponível em: http://www.corteidh.or.cr/docs/casos/articulos/seriec_203_por.pdf. Acesso em: 15 fev. 2021. 
. Caso Trabalhadores da Fazenda Brasil Verde vs. Brasil. Sentença de 20 de outubro de 2016. Acesso em: 15 fev. 2021. Disponível em: http://www.corteidh.or.cr/docs/casos/articulos/seriec_318_por.pdf. Acesso em: 15 fev. 2021.

. Caso Gomes Lund e outros ("Guerrilha do Araguaia”) vs. Brasil. Sentença de 24 de novembro de 2010. Disponível em: http://www.corteidh.or.cr/docs/casos/articulos/seriec_219_por.pdf. Acesso em: 15 fev. 2021.

Caso Herzog e outros Vs. Brasil. Sentença de 15 de março de 2018. Disponível em: http://www.corteidh.or.cr/docs/casos/articulos/seriec_353_por.pdf. Acesso em: 15 fev. 2021.

Caso Nogueira de Carvalho e Outro Versus Brasil. Sentença de 28 de Novembro de 2006. Disponível em: http://www.corteidh.or.cr/docs/casos/articulos/seriec_161_por.pdf. Acesso em: 15 fev. 2021.

COSTA, Eduardo José da Fonseca. Calendarização processual. In: CABRAL, Antônio do Passo. NOGUEIRA, Pedro Henrique (Orgs.). Negócios Processuais. Salvador: Ed. JusPodivm, 2015.

COUTO, Mônica Bonetti; CRUZ, Luana Pedrosa de Figueiredo. Desjudicialização e novo código de processo civil: análise à luz das técnicas inseridas no sistema processual brasileiro. Revista de Processo, v. 271, p. 405-425, set. 2017.

DELDUQUE, Maria Célia; CASTRO, Eduardo Vazquez de. A Mediação Sanitária como alternativa viável à judicialização das políticas de saúde no Brasil. Revista Saúde Debate, Rio de Janeiro, v. 39, n. 105, p. 506-513, abr./jun. 2015. Disponível em: http://www.scielo.br/pdf/sdeb/v39n105/0103-1104-sdeb-39-105-00506.pdf. Acesso em 15 fev. 2021.

FELTEN, Márcia Silvana. O exaurimento do modelo jurisdicional: ponderações sobre um diagnóstico possível. In: SPENGLER, Fabiana Marion. COPELLI, Giancarlo Montagner. JAQUES, Marcelo Dias. O sistema de justiça e suas instituições: ensaios à luz dos direitos humanos e democracia. Santa Cruz do Sul: Essere nel mondo, 2014.

FOGAÇA, Anderson Ricardo. Judicialização da saúde: novas respostas para velhos problemas. Dissertação (Mestrado em Direito). Centro Universitário Internacional UNINTER. Curitiba, 2020.

GICO JR., Ivo Teixeira. A tragédia do Judiciário. RDA - Revista de Direito Administrativo, Rio de Janeiro, v. 267, set./dez. 2014.

A natureza econômica do direito e dos tribunais. Revista Brasileira de Políticas Públicas, Brasília, v. 9, n. 3, 2019. p. 30 e ss.

GRINNOVER, Ada Pellegrini. O processo em evolução. Rio de Janeiro: Editora Forense Universitária, 1999. 
LOPES, Daniel Lozoya Constant. AMADO, Fábio. GONZÁLEZ, Pedro. RÉBORA, Fabian. OS DIREITOS DAS VÍTIMAS AO ACESSO À JUSTIÇA, ÀS GARANTIAS PROCESSUAIS E À REPARAÇÃO INTEGRAL À LUZ DO DIREITO INTERNACIONAL DOS DIREITOS HUMANOS E DA JURISPRUDÊNCIA INTERAMERICANA. CADERNOS ESTRATÉGICOS - ANÁLISE ESTRATÉGICA DOS JULGADOS DA CORTE INTERAMERICANA DE DIREITOS HUMANOS. Disponível em: https://www.corteidh.or.cr/tablas/r39103.pdf Acesso em: 12 fev. 2021

MAZZUOLI, Valerio de Oliveira. Curso de Direitos Humanos. $2^{\mathrm{a}}$ ed. Rio de Janeiro: Método, 2015.

MÜLLER, Julio Guilherme. Negócios Processuais e Desjudicialização da Produção da Prova. 2. ed. Salvador: JusPodivm, 2017.

NUCCI, Guilherme de Souza. Alterações na Lei Maria da Penha trazem resultado positivo. 18 de maio de 2019. Disponível em: https://www.conjur.com.br/2019-mai-18/nuccialteracoes-maria-penha-trazem-resultado-positivo Acesso em: 12 fev. 2021.

ORGANIZAÇÃO DAS NAÇÕES UNIDAS. Declaração Universal dos Direitos Humanos. Disponível em: https://nacoesunidas.org/wp-content/uploads/2018/10/DUDH.pdf. Acesso em: 11 fev. 2021.

ORGANIZAÇÃO DOS ESTADOS AMERICANOS. Convenção Americana de Direitos Humanos. 1969. São José da Costa Rica.

ORGANIZAÇÃO DOS ESTADOS AMERICANOS. Quem somos. 2021. Disponível em: http://www.oas.org/pt/sobre/quem_somos.asp. Acesso em 10 fev. 2021.

Acesso em 06 fev. 2021.

PARANÁ. Ministério Público do Estado do Paraná. Resolução 2002/12 da ONU PRINCÍPIOS BÁSICOS PARA UTILIZAÇÃO DE PROGRAMAS DE JUSTIÇA RESTAURATIVA EM MATÉRIA CRIMINAL. Disponível em: https://juridica.mppr.mp.br/arquivos/File/MPRestaurativoEACulturadePaz/Material_de_Apoi o/Resolucao_ONU_2002.pdf Acesso em: 15 fev. 2021.

WATANABE, Kazuo. Acesso à ordem jurídica justa (conceito atualizado de acesso à justiça) Processos Coletivos e outros Estudos. Belo Horizonte: Editora Del Rey, 2019. 